\title{
COMUNICAÇÃO E CONHECIMENTO: INTERRELAÇÕES QUE PERMEIAM O AMBIENTE ORGANIZACIONAL
}

COMMUNICATION AND KNOWLEDGE: INTERRELATIONS THAT PERMEATE THE ORGANIZATIONAL ENVIRONMENT.

\author{
Ana Maria Teixeira Maciel ${ }^{1}$ \\ Rosana Cristina Vilaça Pimentel ${ }^{2}$ \\ Marlene Marchori ${ }^{3}$
}

\begin{abstract}
Resumo: A construção de conhecimento é inerente aos processos organizacionais, sendo, portanto, natural nas organizações. Essa abordagem confere reconhecer a comunicação enquanto alicerce, ou seja, fundamento do desenvolvimento do conhecimento pelas pessoas por meio de seus processos de interação. Esse artigo analisa a influência da comunicação no processo de criação de conhecimento da Angelus Ciência e Tecnologia S.A., empresa de base tecnológica. A análise teve como ponto de partida o estudo de questões relacionadas à comunicação e sua relevância na espiral do conhecimento de Nonaka e Takeuchi. A metodologia proposta é de natureza qualitativa, de caráter descritivo e exploratório, tendo utilizado como técnica de pesquisa, entrevistas em profundidade. Este artigo revela a comunicação como elemento integrante da construção de conhecimento, a qual acontece não só pela troca de informações, mas pelas conversações que emanam das pessoas nos seus relacionamentos, trazendo experiências e vivências que desenvolvem os indivíduos, as organizações e consequentemente a sociedade.
\end{abstract}

Palavras-chave: Comunicação. Conhecimento. Gestão do conhecimento. Construção de conhecimento.

\begin{abstract}
The construction of knowledge is inherent to organizational processes and is therefore natural in organizations. These approaches recognize communication as a foundation, that is the basis of the development of knowledge in organizations through people by its interactional processes. This article analyzes the influence of communication in the process of knowledge creation at the Angelus, Science and Technology SA, a technology-based company. The analysis took as its starting point the study of issues related to communication and its relevance in the knowledge spiral of Nonaka and Takeuchi. The proposed methodology is a qualitative, descriptive and exploratory, and used as a research technique, in-depth interviews. This article reveals communication as an integral part of the construction of knowledge, which happens not only through the exchange of information, but also through the conversations that emanate from people in their relationships, providing experiences that develop individuals, organizations and consequently society.
\end{abstract}

Keywords: Communication. Knowledge. Knowledge management. Construction of knowledge.

\footnotetext{
${ }^{1}$ Especialização MBA Gestão de Pessoas. Universidade Estadual de Londrina. E-mail: ana.t.maciel@gmail.com

${ }^{2}$ Especialização MBA Gestão de Pessoas. Universidade Estadual de Londrina. E-mail: rosanavilaca@sercomtel.com.br

${ }^{3}$ Doutora em Ciências da Comunicação. Professora do Programa Pós-Graduação em administração Universidade Estadual de Londrina. E-mail: ana.t.maciel@gmail.com

Enviado em: 20/06/2012 - Aceito em: 10/04/2013.
}

\begin{tabular}{|l|l|l|l|l|l|l|} 
(C) Rev. digit. bibliotecon. cienc. inf. & Campinas, SP & v.11 & n.2 & p.98-122 & maio/ago. 2013 & ISSN 1678-765X \\
\hline
\end{tabular}




\section{INTRODUÇÃO}

Temas como capital humano, capital intelectual, inteligência competitiva e gestão do conhecimento vêm se tornando palavras de ordem, em razão do ambiente competitivo em que se inserem as organizações.

O conhecimento das organizações é questão estratégica nos processos econômicos. Os investimentos nos ativos intangíveis, como o capital intelectual, crescem mais rápido do que os investimentos nos ativos físicos ou tangíveis (FLEURY; OLIVEIRA JR, 2002). A valorização do capital intelectual, na contemporaneidade, tem levado as organizações a buscarem gerenciarem o conhecimento, uma vez que as questões que permeiam sua construção e propagação são fundamentais para a geração de riquezas nos ambientes organizacionais (KLEIN, 1998). A relação entre conhecimento e comunicação é a abordagem principal desse artigo. Ressalta-se de um lado a necessidade dos indivíduos apropriarem conhecimento e expandirem o seu repertório e de outro compreender como o conhecimento nos contextos organizados, se torna organizacional (TSOUKAS; VLADIMIROU, 2001).

O conhecimento é construído e reconstruído nas práticas diárias em função dos inúmeros diálogos que ocorrem no dia-a-dia de uma organização (MARCHIORI; CONTANI; BUZZANELL, 2011), sendo sua criação um processo dinâmico e constante. $\mathrm{O}$ conhecimento surge de diferentes perspectivas, podendo ser rotinizado, por meio da comunicação como transmissora de informações; emergente, o qual engloba teorias da construção da realidade; e o conhecimento político, entendido como resultado da confluência de interesses e relações de poder (MURPHY; EISENBERG, 2011).

Neste contexto, destaca-se a comunicação, elemento influente na criação de conhecimento, uma vez que acontece se constitui através de processos complexos de compartilhamento de informações (ALCARÁ, 2009), levando em consideração a dinâmica dos processos (BERLO, 1999). Tendo em vista que o ato de comunicar-se é inerente às relações humanas, entende-se que estas são responsáveis pela como elemento fundamental na dinâmica da geração de difusão do conhecimento organizacional. A interação entre conhecimento e comunicação, permeada pelas 
relações humanas, será então objeto desse estudo, a partir do entendimento de que tal interação é questão primordial para o desenvolvimento contínuo das organizações.

Ao se considerar essas reflexões teóricas, o presente artigo busca analisar a influência da comunicação no processo de criação de conhecimento na empresa Angelus. Por conseguinte, apresenta-se conceitos e inter-relações a respeito do conhecimento e da comunicação, uma vez que o estudo e o entendimento destes temas são primordiais para se compreender a comunicação no processo de construção de conhecimento. Tal abordagem teórica e a estruturação do referencial teórico permitiu o desenvolvimento da pesquisa empírica qualitativa, a qual teve como estratégia o estudo de caso único na organização Angelus Indústria de Produtos Odontológicos S/A.

Para atingir esse objetivo o artigo estrutura-se na reflexão inicial sobre os conceitos que embasam esses campos de conhecimento. A fim de que o objetivo deste artigo seja alcançado de maneira concisa, sua estrutura corresponde ao seguinte: introdução; explanações sobre a comunicação, suas dimensões e fluxos; gestão e construção do conhecimento; na sequência reflete seguido de reflexões sobre a relação entre conhecimento e comunicação, ilustrando com o estudo de caso desenvolvido no campo empírico, cujas principais conclusões ressaltam o valor dessa relação.

\section{A COMUNICAÇÃO}

No ambiente organizacional, observam-se pessoas, processos, práticas nos quais, por meio do trabalho coletivo, busca-se atingir objetivos que contribuam para o bem estar social, econômico e ambiental, de acordo com o contexto em que a organização está inserida. Portanto, a realidade organizacional é socialmente construída através da comunicação, a qual pode acontecer fundamentalmente pela interação entre os indivíduos (PUTNAM, 1982). Neste sentido, não se concebe uma organização sem comunicação (TAYLOR, 1993).

Shannon e Weaver (1949) são considerados os precursores da abordagem do processo de comunicação, em que o transmissor ao emitir a mensagem deve estar atento à fluidez do processo para o adequado recebimento da informação pelo receptor, considerando a possibilidade do surgimento de ruídos neste processo, Berlo 
(1999) ressalta a importância da escolha dos canais para na efetividade da comunicação. O processo de comunicação pode ser considerado uma sequência de atividades na qual se faz necessário isolar os fatores que fazem ou não diferença no seu desenvolvimento. É compreendido ainda como um fenômeno dinâmico que apresenta contínua transformação no tempo ou qualquer tratamento ininterrupto (BERLO, 1999).

Por comunicação, entende-se a capacidade de trocar ou discutir ideias, de dialogar, de conversar, buscando o bom entendimento entre as pessoas (FERREIRA, 1986). Esta definição demonstra a necessidade não só da troca de informações entre os indivíduos, mas da construção de sentido para que o processo de comunicação se efetive, como explorado nesse artigo. A comunicação pode também ser compreendida como fluxos de mensagens processadas em redes de relações interdependentes (GOLDHABER, 1991). Neste aspecto, é percebida como um processo através do qual os indivíduos obtêm as informações pertinentes sobre a organização e as mudanças que nela ocorrem (KREPS, 1990).

Dessa forma, a comunicação pode ser considerada elemento central das organizações, um alicerce que molda a organização, fazendo-a ser aquilo que ela é (CARDOSO, 2006). Conceituar a comunicação nos ambientes organizacionais significa observar suas dimensões física, sensorial, racional, emocional, social, ética, estética e valores. Ao se comunicarem, as pessoas agem em todas elas (SCHULER et al, 2004).

\section{Dimensões e Fluxos da Comunicação}

Kunsch (2003) observa três dimensões da comunicação: a instrumental, a humana e a estratégica. Na dimensão instrumental, a comunicação é um canal de envio e recebimento de informações, um instrumento que viabiliza a troca de mensagens. Já sobre na dimensão estratégica, a comunicação é tratada como elemento estratégico e como parte da administração geral para que agregue valor à empresa, tornando-a forte em seu ambiente mercadológico. A dimensão humana apresenta uma perspectiva mais humanista e social, pois pretende, através de esforços de comunicação, tratar tanto o público interno como o externo como verdadeiros cidadãos (KUNSCH, 2003). Esta dimensão é capaz de gerar em uma organização um 
ambiente propício para relacionamentos interpessoais o que certamente acresce qualidade nas relações cotidianas de trabalho.

Este artigo vislumbra a dimensão humana na criação do conhecimento, pois é necessário que haja comportamento comunicacional entre um grupo para que ocorra a difusão e a troca de informações.

Neste sentido, a comunicação deixa de ser apenas informacional, ou seja, um processo mecânico de transmissão de mensagens de um emissor para um receptor, evoluindo para a relacional, observada como um processo de compartilhamento entre interlocutores, que constroem sentido na interação que estabelecem, em que os elementos se afetam mutuamente e, na relação, reconfiguram a si próprios e também a sociedade (MAIA, FRANÇA, 2003; LIMA, BASTOS, 2008).

Importante ressaltar que o sucesso da comunicação, seja informacional ou relacional, não depende apenas de um processo adequado, mas essencialmente da influência das redes formais e informais e dos fluxos comunicacionais que podem dinamizá-lo, facilitando tanto a disseminação quanto os processos interacionais.

A comunicação flui basicamente através de duas redes, a formal e a informal. A rede formal caracteriza-se pelo conjunto de canais e meios de comunicação, construídos de forma consciente e deliberada. Nesta rede, a comunicação emana da organização por diversos veículos, tais como impressos, visuais, auditivos, eletrônicos etc., expressando informes, ordens, recomendações, pronunciamentos, nos quais a informação perpassa formalmente por distintas unidades de trabalho (VALENTIM, 2002; KUNSCH, 2003).

A rede informal, por sua vez, se fundamenta nas relações sociais nas quais a comunicação emerge das relações entre as pessoas, e ocorre nos níveis estratégico, tático e operacional (KUNSCH, 2003; MONTEIRO, VALENTIM, 2008). A existência dos canais informais é justificada pela necessidade do indivíduo em obter informações sobre a organização e sobre a forma como as transformações que nela ocorrem afetam suas vidas (KUNSCH, 2003).

Além das redes formais e informais, Kunsch (2003) afirma que a comunicação pode ocorrer em fluxos, sendo eles: descendente ou vertical, ascendente, horizontal ou lateral, transversal ou longitudinal e circular. No fluxo descendente, a comunicação é de cima para baixo, traduzindo normas e diretrizes da organização. O contrário ocorre 
no fluxo ascendente, no qual as pessoas situadas em posição inferior enviam suas informações à cúpula, por meio de instrumentos planejados. Já o fluxo horizontal ocorre no mesmo nível, entre os pares ou em posições hierárquicas semelhantes, sendo que a comunicação se processa entre os departamentos, unidades de negócios. Quando bem conduzida resulta na otimização do desempenho da organização.

No fluxo transversal, a comunicação se dá em todas as direções, fazendo-se presente nos fluxos ascendente, descendente e horizontal, ou seja, permeia distintas unidades organizacionais e níveis hierárquicos. Desta forma, depende de uma gestão que proporcione condições para que as pessoas interfiram em diferentes áreas. Por fim, o fluxo circular envolve todos os níveis sem se ajustar às direções tradicionais, seu conteúdo é amplificado quanto maior as relações interpessoais entre os indivíduos (KUNSCH, 2003).

Observa-se, pela descrição destes fluxos, que a comunicação está relacionada aos processos organizacionais, podendo ser vista como o substrato da organização. Com efeito, tais processos requerem a construção de conhecimento para que os indivíduos se desenvolvam nas organizações, visto que, na atualidade, busca-se além do crescimento profissional, o pessoal (TEIXEIRA FILHO, 2000).

\section{O conhecimento e sua gestão}

Tendo em vista a imprescindibilidade da comunicação nos processos de geração de conhecimento nas organizações, Angeloni (2003) apresenta uma contribuição relacionando dado, informação e conhecimento no processo entre emissores e receptores, temas definidos na sequência, os quais compõem a geração do conhecimento organizacional.

Por dado entende-se a matéria prima da informação (ANGELONI, 2003; SILVA, 2004) e para que tenha sentido, deve estar estruturado (ALVARENGA, 2008). Para Angeloni (2003), as informações são dados com significados, logo, o dado não se faz sem informação, tida como uma afirmação válida, codificada para uma comunicação efetiva. Desta forma, os dados quando estruturados em informação resultam em conhecimento, ou seja, a informação eficaz em ação, que, por seu turno, é processada pelos indivíduos, como um subconjunto de informações (DRUCKER, 1999; PROBST, RAUB, ROMHART, 2002; CAMPOS, 2007). Observa-se pelas 
definições que dados são pré-requisitos para informação e esta é pré-requisito para conhecimento (SILVA, 2004).

Nota-se que o conceito de conhecimento contém um sentido mais complexo, visto que "conhecer é um processo de compreender e internalizar as informações recebidas combinando-as de forma a gerar mais conhecimento" (MERTON apud GONÇALVES, 1995, p. 311). Choo (2003) aponta que o conhecimento é disseminado sob várias formas nas organizações. Para o autor, o conhecimento resulta da especialização e da experiência de seus membros, através das informações que adquire, das situações que experimenta em seu ambiente e também a partir do que já viveu (ALVARENGA, 2008).

Para que o conhecimento existente na organização seja disponibilizado àqueles que precisam dele, o mesmo deve ser traduzido, uma vez que desta maneira os indivíduos possam aprender, distribuir e utilizar o conhecimento. Assim, faz-se necessária uma gestão especializada, entendida por Murray (apud LEITE, 2006, p. 93) como "uma estratégia que transforma bens intelectuais da organização - informações registradas e o talento dos seus membros - em maior produtividade, novos valores e aumento de competitividade". Segundo Leite (2006), a informação refere-se ao conhecimento explícito, e o talento, por sua vez, está relacionado ao conhecimento tácito.

O conhecimento explícito pode ser facilmente codificado, podendo ser processado por computador, transmitido eletronicamente, ou armazenado em banco de dados. Por isso, para que os aspectos subjetivos do conhecimento tácito sejam compartilhados na organização, é preciso que sejam convertidos em conhecimento explícito, colaborando para a criação do conhecimento (NONAKA; TAKEUCHI, 1997).

O conhecimento tácito, por seu turno, é pessoal e está relacionado à experiência e à ação do ser humano, assim como os ideais, valores e emoções. Nonaka e Takeuchi (1997) explicam que esse conhecimento pode ser dividido em duas dimensões: técnica e cognitiva. A técnica inclui as habilidades contidas no knowhow e a cognitiva é constituída por modelos mentais, crenças e percepções tão enraizadas a ponto de não serem percebidas. 
As abordagens para a gestão do conhecimento tratam as melhores formas de como as organizações criam, compartilham e utilizam o conhecimento disponível, tanto explícito quanto o tácito, evidenciando, muitas vezes, a ideia de processo, em que a comunicação atua no sentindo de oferecer suporte eficaz para o agir e o existir das organizações tornando-se sustentável na construção de conhecimento (CARDOSO, 2006). Teixeira Filho (2000) reforça esta reflexão ao observar tal gestão como uma coleção de processos que governam a criação, a disseminação e a utilização do conhecimento. Fica claro que a geração de conhecimento depende desses dois tipos de conhecimento e de sua interação, questão já levantada por Polanyi na década de 60 (POLANYI, 1969 apud HENRIQUE; BARBOSA, 2005). O esforço individual somado a práticas coletivas constituem os diversos tipos de saber (HENRIQUE; BARBOSA, 2005).

Entretanto, para além da gestão do conhecimento, é preciso atentar-se para a sua criação, definida por Nonaka e Takeuchi (1997) como a capacidade que uma organização tem de criar conhecimento, disseminá-lo e incorporá-lo aos seus produtos, serviços e sistemas. Para Nonaka e Takeuchi (1997), o conhecimento é criado pelos indivíduos através da interação entre o conhecimento tácito e o explícito, que por sua vez, de acordo com Silva (2004), resultam na principal dinâmica da criação do conhecimento nas organizações. O processo de produção de conhecimento está diretamente vinculado a sua conversão que, segundo Nonaka e Takeuchi (1997), ocorre de quatro maneiras, conforme demonstrado na Figura 2:

Figura 2 - Os processos de conversão do Conhecimento de Nonaka e Takeuchi.

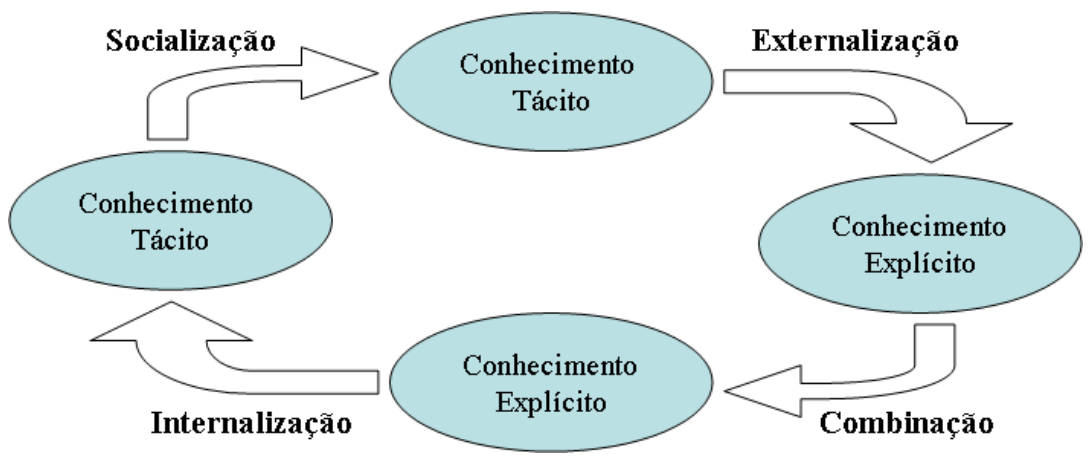

FONTE: MORESI (2000, p. 36) 
Como ilustrado na Figura 2, a conversão do conhecimento tácito para explícito é denominada externalização, um processo de articulação do conhecimento tácito em conceitos explícitos, normalmente provocada pelo diálogo e ou pela reflexão coletiva, através de vias informais (MORESI, 2000; DAZZI, ANGELONI, 2004; ORSI, 2004).

Do explícito para o explícito, tem-se a combinação, a qual envolve a associação de conhecimentos explícitos, pela troca de conhecimento contido em documentos, reuniões, conversas ao telefone ou redes de comunicação (MORESI, 2000; ORSI, 2004). Pode ser tida como a conversão de algum tipo de conhecimento explícito gerado por um indivíduo para agregá-lo ao conhecimento explícito da organização (SILVA, 2004).

A conversão do conhecimento explícito para tácito ocorre por meio da internalização que é o processo de incorporação do conhecimento explicito no tácito (MORESI, 2000). De maneira mais direta, é o 'aprender fazendo', ocorre pela verbalização e estruturação do conhecimento sob a forma de documentos (ORSI, 2004).

Por fim, a conversão do conhecimento tácito para tácito, a socialização, se baseia no compartilhamento de experiências, criando conhecimentos tácitos como modelos mentais ou habilidades técnicas compartilhadas (MORESI, 2000). Dá-se por meio da observação, imitação e prática (ORSI, 2004).

O conteúdo criado por cada modo de conversão é naturalmente diferente. A socialização gera o conhecimento compartilhado, a externalização gera o conhecimento conceitual, a combinação dá origem ao conhecimento sistêmico e a internalização produz o conhecimento operacional (ORSI, 2004). Choo (2003) esclarece que estas etapas de conversão se retroalimentam incessantemente, visto que o novo conhecimento deve ser socializado, entre os demais membros da organização.

Contudo, a gestão do conhecimento não se restringe a gerir ativos do conhecimento, e sim os processos que os influenciam, incluindo desenvolvimento, preservação, uso e compartilhamento do conhecimento, ou seja, a comunicação (ALVARES; BAPTISTA; ARAÚJO JR, 2010).

\section{REFLEXÕES SOBRE A RELAÇÃO ENTRE CONHECIMENTO E COMUNICAÇÃ̃O}


Os conceitos relativos ao conhecimento e a comunicação vêm conquistando valor no âmbito organizacional, uma vez que tais elementos são cada vez mais reconhecidos como recursos indispensáveis para o sucesso. A comunicação é fundamental para realização das atividades empresariais, nas quais os indivíduos adquirem conhecimento por meio do uso da informação em suas ações (ANGELONI, 2003; SCHULER ET AL, 2004).

$\mathrm{Na}$ rotina organizacional, é importante ter disponíveis dados, informações e conhecimentos, mas esses normalmente estão dispersos, fragmentados e armazenados na cabeça dos indivíduos, sofrendo interferência de seus modelos mentais. Pereira e Fonseca (1997) salientam que para apreensão das informações num determinado contexto, é necessário uma ampliação da percepção dos indivíduos frente à realidade, uma vez que seu modo de viver induz a um estreitamento perceptivo e a uma visão de mundo restrita e fragmentada. Sendo assim, além da preocupação em obter os dados, informações e conhecimentos, é valido atentar-se para as distorções que as informações estão sujeitas em sua decodificação.

Pode-se observar que a comunicação leva a um maior aproveitamento das informações, à medida que os indivíduos processam, compreendem e dão sentido as informações, fazendo que naturalmente evoluam para conhecimentos.

Os elementos da comunicação estão inseridos no processamento das informações para geração de conhecimento. Partindo da premissa de que a transmissão de informações permeia a dinâmica organizacional pode-se entender a organização como um estoque de conhecimento, que consiste basicamente em como a informação é codificada e disponibilizada para aplicação (FLEURY; OLIVEIRA JR. 2001). Desta forma, a informação quando assimilada, produz conhecimento (BARRETO, 1994). Pela perspectiva da comunicação ao registrar um conhecimento, presume-se que há intuito de comunicá-lo, de transmiti-lo a alguém, fazendo assim com que tenha sentido (TEIXEIRA FILHO, 2000).

Soma-se a esta reflexão os aspectos da comunicação informacional e relacional. A comunicação informacional seria na prática, informações transmitidas através de murais, intranets, informativos, manuais. Por outro lado, a comunicação relacional envolve as pessoas, seja na execução de determinada atividade ou na 
discussão para resolução de problemas, o que sugere que a comunicação emana justamente da interação entre estas pessoas.

$\mathrm{Na}$ ótica deste estudo, para que o conhecimento tenha sentido, faz-se necessária a comunicação sob a perspectiva relacional, para que através do relacionamento, os indivíduos construam significados e compartilhem habilidades. Sendo assim, sob o aspecto relacional, para que exista comunicação, é pressuposto que exista uma relação, um compartilhamento de expectativas entre o emissor e o receptor da mensagem (LIMA; BASTOS, 2008), em que o emissor ao fazer-se entender, sofre interferência do receptor modificando e ressignificando o contexto frente à ambiguidade, já que nem sempre os entendimentos do receptor são os inicialmente pretendidos pelo emissor (RIBEIRO; MARCHIORI, 2008).

Neste aspecto, o processo interativo vias formais e informais contribuem para a criação de conhecimento (NONAKA; TAKEUCHI, 1997). As vias formais contribuem para que novos conhecimentos gerados não se percam, sejam documentados e multiplicados para os demais envolvidos, construindo assim mais conhecimento. Analisando as vias informais percebe-se que há a intensificação das relações entre os indivíduos, para que haja compartilhamento não só de informações, mas também de conhecimentos adquiridos através das experiências e habilidades individuais.

Dessa maneira, Camatti e Fachinelli (2010) consideram a construção de conhecimento como a validação do conhecimento explícito pela experiência, em que esta é a forma padrão do conhecimento tácito, que quando disseminado, sedimenta o conhecimento explícito. Visto que nem sempre a percepção individual representa a realidade contextual, pode-se dizer que o conhecimento tácito possui limitações e, a fim de amenizá-las, é necessário que haja interação entre indivíduos através do diálogo, do contato e da troca de informações, ou seja, o conhecimento deve estar ligado ao ato de comunicação. Esta reflexão sugere que se faz essencial intensificar os processos de comunicação nas organizações, visto que estes auxiliam na explicitação do conhecimento (DAZZI; ANGELONI, 2004).

Sendo assim, para o alcance do sucesso relacionado à criação de conhecimento, a comunicação deve atuar no desencadear do fluxo da informação e do conhecimento (ALCARÁ; 2009). Tucker, Meyer e Westerman (1996) afirmam que a 
comunicação não só deve atuar como agente, como deve ser considerada responsável pelo fluxo transfuncional e multilateral da informação e do conhecimento na organização. Este processo associado à gestão do conhecimento atua para que os conhecimentos gerados incessantemente sejam organizados e utilizados a fim a gerar valor para a organização (DAZZI; ANGELONI, 2004).

\section{PROCEDIMENTOS METODOLÓGICOS}

Com base nos objetivos propostos para este estudo, a abordagem da pesquisa configura-se como qualitativa, exploratória e descritiva (GODOI; BALSINI, 2006). Justifica-se tal classificação, pois por meio desta pesquisa, busca-se descrever e compreender o processo de criação de conhecimento na empresa para que seja possível analisar a influência da comunicação de maneira aprofundada e detalhada.

Adotou-se como estratégia o estudo de caso único, a fim de que fosse possível compreender os processos e as interações sociais de conhecimento e comunicação que se desenvolvem nas organizações (HEARTLEY; 1995). Para unidade de análise deste estudo de caso, foi selecionada a empresa Angelus Indústria de Produtos Odontológicos S/A, por meio da amostra intencional.

A Angelus é uma empresa nacional que atua no desenvolvimento, produção e comercialização de produtos odontológicos. Está localizada em Londrina e atua nas áreas de endodontia, dentística, prótese e prevenção. A empresa conta com 60 colaboradores distribuídos da seguinte forma: $46 \%$ atuam na área administrativa; $26,7 \%$ exercem atividade operacional; $11 \%$ atuam nas atividades de P\&D; $10 \%$ são executivos e $5 \%$ supervisores.

Como técnicas de pesquisa, optou-se por entrevistas em profundidade (GODOY, 2006), realizadas no mês de dezembro de 2011, a partir de um roteiro semi-estruturado dentro das categorias: comunicação, conhecimento e suas interrelações. Tal estrutura foi delineada no sentido de compreender os significados que os entrevistados atribuíram às questões e situações relativas à influência da comunicação no processo de construção de conhecimento.

As entrevistas foram realizadas com profissionais lotados no departamento de Pesquisa e Desenvolvimento (P\&D) da empresa em estudo. Este setor é composto por 10 colaboradores, mestres, doutores e pós-doutores, sendo que a amostra dos 
entrevistados representou $60 \%$ desta população: três pessoas do sexo masculino e três do sexo feminino, com idades entre vinte e sete a quarenta e três anos, nos cargos de Gestor e Pesquisadores, com tempos de empresa entre um ano e oito meses e seis anos.

Parte-se então para o uma breve explicação sobre o campo empírico, com intuito de oferecer entendimento sobre o contexto onde está inserida a organização estudada e suas relações com as duas principais categorias abordadas por este artigo: o conhecimento e a comunicação.

\section{O campo empírico}

A Angelus Indústria de Produtos Odontológicos S/A foi fundada em 20 de setembro de 1994, a partir da criação de um produto inovador. A empresa investe em inovação tecnológica, atuando juntamente com o setor acadêmico, técnico e científico, por meio da participação de universidades e centros de pesquisa no desenvolvimento dos produtos.

Este é um aspecto que revela a necessidade de um processo de gestão de conhecimento que colabore para a propagação dos novos conhecimentos internamente e que, do mesmo modo, seja permitido que a partir da interação organizaçãouniversidade-centros de pesquisa possam ser construídos conhecimentos com aplicabilidade, de modo a atender as necessidades do mercado, gerando valor para a organização.

A questão do conhecimento é tratada pela Angelus a partir da coordenação de ações de suporte ao desenvolvimento de novos produtos e à melhoria dos processos da empresa. A comunicação se faz presente em todos os processos, com vistas a propiciar a todos os níveis de colaboradores o conhecimento, entendimento e acompanhamento do negócio. Considerando o negócio da Angelus, observa-se a comunicação como um pilar, que sustenta a gestão e o desenvolvimento de projetos.

A escolha do setor de Pesquisa e Desenvolvimento para a realização das entrevistas em profundidade se deu em função da sua relevância para o negócio e por haver foco na criação de novos conhecimentos. Este contexto despertou interesse sobre a forma como interagem os indivíduos envolvidos através da comunicação para construção de conhecimento. Neste setor, a comunicação ocorre através de vias 
formais e informais em todas as direções, sendo que as vias formais são consideradas mais importantes à medida que contribuem para que os conhecimentos não se percam e possam ser utilizados no momento em que são requisitados.

Como estratégias de comunicação formal, o setor de P\&D, utiliza e-mail, Skype e intranet. $\mathrm{Na}$ atualidade, como principal ferramenta de comunicação é utilizada a Gestão a Vista, um mural alimentado de informações à medida que projetos avançam simultaneamente. Esta forma de gestão tem contribuído para o acompanhamento dos projetos, posicionando todos os indivíduos envolvidos, sobre suas responsabilidades em cada projeto a evolução do seu trabalho e os próximos passos a serem dados. Já no aspecto informal, além das conversas multidepartamentais, realizam-se reuniões para discussão de ideias e cafés com o presidente, os quais constroem relacionamentos que sugerem a fluidez da comunicação organizacional.

\section{APRESENTAÇÃO E ANÁLISE DE RESULTADOS}

Esse relato prioriza as categorias abordadas no roteiro de pesquisa respeitando a análise da organização sob a perspectiva dos indivíduos em três categorias: comunicação, conhecimento e as inter-relações entre estes dois elementos.

No que tange à comunicação, esta é considerada pelos entrevistados como fundamental, sendo vista por estes, como estratégica. Nota-se este valor nos depoimentos:

"Eu posso te afirmar que a comunicação é fundamental não só no caso da Angelus, mas para qualquer organização. No caso de projetos a comunicação é fundamental ela acaba suportando a estratégia da empresa. Então eu diria que estratégico com certeza". (Entrevistado A).

Estas colocações reforçam a comunicação estratégica no sentido de disseminação de informações, que se revela no estudo teórico como aquela que agrega valor à empresa e a torna forte em seu ambiente mercadológico, alcançando objetivos no longo prazo.

Um aspecto interessante observado nas entrevistas foi em relação à importância dada à comunicação, em razão da estrutura de trabalho apresentada pelo grupo, tendo em vista a participação de equipes heterogêneas alocadas em diferentes 
departamentos, em razão da existência de uma estrutura matricial na criação de projetos.

"Então, a gente trabalha numa estrutura matricial, estrutura matricial significa dizer o seguinte, que em determinados momentos do projeto eu vou pegar pessoas que estão alocadas em outros departamentos e eles vão ceder uma parte do tempo deles para o projeto. Então ele tem por assim dizer um chefe funcional e tem que responder ao projeto, pra que isto funcione a comunicação é fundamental, porque qual é a prioridade que ele dá, pras atividades funcionais, ou pras atividades do projeto". (Entrevistado A).

Apesar de a teoria afirmar que a comunicação está presente não só no nível informacional, mas também no nível relacional, percebe-se que a importância da comunicação neste estudo está basicamente centrada como um aspecto de apoio no desenvolvimento de projetos do que necessariamente como mobilizadora dos projetos, conforme declarações abaixo:

“Então, na minha visão o que contribui mesmo é a formal. E a norma tem esta preocupação de padronização de caminhos formais de comunicação, a gente tem investido neste sentido porque a gente percebe que, se tem um aspecto de repente negativo de ter uma burocratização com engessamento, você ganha na documentação e nas aquisições apreendidas". (Entrevistado A).

“Então, o que acontece, faz a reunião em frente ao painel e resolve o que está pendente e o que está para vir. Definindo quem vai fazer as atividades, então esta é uma ideia de diminuir este problema de comunicação. Então você fez a reunião, meio que você escreveu, escreveu o que tem que fazer e a pessoa responsável". (Entrevistado B).

Refletindo sobre questões teóricas da comunicação e informação é válido considerar que apesar de a informação ser tida como matéria prima da comunicação, nem sempre uma informação produz comunicação, já que não há comunicação através da informação sem que haja o entendimento pelo receptor.

“A informação tem que estar disponível sempre, você não pode ficar sem a informação, principalmente parte de projeto, porque pode ser uma informação que você não tenha, mas está disponível e você não teve acesso, você pode travar o andamento do projeto". (Entrevistado B). 
Neste sentido, vale refletir que problemas na transferência de informações podem ser prejudiciais não só por falhas no processo de comunicação, no que diz respeito à informação chegar ou não. Deve-se considerar que as informações codificadas pelos receptores podem se diferenciar, devido a distorções ocasionadas por características pessoais e modelos mentais de cada indivíduo, que podem ocasionar problemas de comunicação (ANGELONI, 2003). O processo de comunicação é dinâmico, e no campo da gestão do conhecimento não é diferente, pois interage e integra a informação e a experiência para criar e expandir o conhecimento (CAMATTI; FACHINELLI, 2010).

Como exemplo, verificou-se nas análises das entrevistas, que os departamentos, por fazerem parte de uma estrutura matricial, dependem uns dos outros para a execução das atividades relacionadas aos projetos. No entanto, notaramse circunstâncias em que há a mobilização das informações e outras em que as mesmas não são completamente transmitidas, o que acaba sendo prejudicial para o processo de gestão do conhecimento.

Discutida a questão da informação, observa-se, na opinião dos entrevistados, como se mostra a comunicação tanto em via formal quanto informal, as quais se manifestam por meio de diálogo, discussão, reunião, e-mails, skype, intranet, mural, painel e vídeo conferência. Há grande valorização da rede formal que, na visão do grupo entrevistado, contribuem para a estrutura da organização, uma vez que as lições aprendidas são documentadas para que sejam convertidas em conhecimento.

"Então, normalmente é mais por e-mail ou por reuniões agendadas ou por reuniões de última hora, já que tá todo mundo aqui vamos fazer uma reunião de quinze minutos. Pra geração é a formal, o que você discutiu você coloca no papel pra seguir as normas que nós temos que é a CE, a Anvisa e a ISO". (Entrevistado B).

"Também tem divulgações via intranet dependendo do assunto do que se trata. A gente também trabalha com Skype, às vezes, quando precisa fazer alguma vídeo conferência, alguma coisa deste tipo". (Entrevistado C).

Os entrevistados demonstram que as vias formais devem andar paralelamente com as vias informais, pois a geração de conhecimento começa informalmente no diálogo e na interação, para posteriormente ser documentado. De fato, a comunicação 
deve fluir em todos os sentidos na organização, segundo Kunsch (2003), o sistema formal é suplementado, por uma rede informal de comunicação, igualmente importante, que se baseia nas relações sociais intra-organizativas.

Também é salientado nas entrevistas que a comunicação, através das redes formais, facilita o entendimento ao minimizar os ruídos no processo. Para Robbins (2002), os canais formais e informais diferem em relação à capacidade de transmitir informações. Para o autor, a conversa face a face proporciona maior entendimento à medida que se observa, além da informação, a postura, expressão facial, gestos e entonações proporcionados pelo ato presencial. Mesmo que as conversas e os diálogos não tenham sido referenciados como canal de comunicação, este aspecto se manifesta nas falas dos sujeitos entrevistados.

"Você observa muitas vezes que um gesto ou um sinal no corredor, diz mais coisas que um e-mail formal, mas existem as duas coisas, você tem que ter as duas coisas caminhando em paralelo". (Entrevistado D).

"Tudo o que você fez informalmente, pra você consegui ir em frente com o projeto, você tem que estar com tudo no papel depois que você definiu na informal, tanto é que a gente tem vários formulários desde a idéia do projeto até o que seria o pré-projeto". (Entrevistado B).

Observa-se que tanto a comunicação formal quanto a informal interagem no ambiente da Angelus. Partindo-se especificamente para as análises dos fluxos, observou-se que na opinião dos entrevistados, a comunicação ocorre em todas as direções e, desta forma, interligam unidades distintas de trabalho em diversos níveis hierárquicos.

"Aqui é acesso livre, você pode pegar e conversar com o CEO, ou o gerente do projeto, a gente tem acesso a todos os envolvidos no projeto". (Entrevistado B)

"O acesso ele é muito direto tanto entre os pares, quanto em outros departamentos com alguém que esteja numa posição hierárquica acima ou abaixo". (Entrevistado C)

$\mathrm{Na}$ organização, os fluxos de comunicação se relacionam na medida em que há necessidade de buscar conhecimento ou informação entre os pares ou em outros departamentos. Desta forma, as opiniões do grupo entrevistado indicam que na 
Angelus todos interagem de forma livre, o que sugere a predominância da comunicação mediante o fluxo circular. Conforme os entrevistados,

"Tudo depende do objetivo a que está se procurando, então pode ser que você esteja trabalhando com um conhecimento tão especifico que conversar com o par te fornece muito mais informações, às vezes é algo que você não tem conhecimento, você não tem habilidade especifica pra isto e aí às vezes conversar com uma pessoa totalmente desligada ao departamento, por aquilo que você faz especificamente ai você pode trazer muito mais conhecimento neste sentido". (Entrevistado C).

Desse modo, através das redes e fluxos de comunicação perpassam as informações e conhecimentos, sendo assim disseminados e compartilhados. Na organização estudada, a disseminação de informações ocorre basicamente através de seminários, treinamentos, documentos e reuniões.

"Ele acompanha uma pessoa que já trabalha naquilo, ou que já tem um pouco mais de experiência naquilo para poder ser inserido no meio". (Entrevistado C)

“Através de seminários, através de treinamentos, através de vários treinamentos, tem épocas no ano que os treinamentos são para o pessoal de campo, ou para o pessoal da produção". (Entrevistado D)

Já o compartilhamento de informações e conhecimentos no departamento de $\mathrm{P} \& \mathrm{D}$, conforme mencionaram os entrevistados, ocorre no contato diário, através da emissão de opiniões. Para Albagli e Maciel (2004), a difusão e o compartilhamento requerem que os atores estejam conectados, que haja canais ou mecanismos de comunicação que propiciem os vários fluxos de conhecimento. Os depoimentos reforçam a discussão:

"Aí falando do departamento de P\&D, ela se dá no contato diário, eu como gestor dou liberdade para que os pesquisadores emitam sua opinião, já teve casos de mudar significativamente $\mathrm{o}$ escopo do projeto em função da experiência e conhecimento prévio do pesquisador". (Entrevistado A)

"A gente tem abertura para falar, a gente tem vários momentos para isto". (Entrevistado E).

"A gente já desenvolveu alguns trabalhos com reuniões mais formais onde cada um expunha o que sabia aquilo que tem mais facilidade". (Entrevistado C). 


\section{SUGESTÃO}

Um ponto destacado por um dos entrevistados resgata a transferência de informações através da comunicação relacional, que muito mais que transmitir informações, oferece oportunidade para que as pessoas se relacionem.

"Eu acho que muito mais que seminários é o dia a dia de você estar acompanhando de perto e tirando dúvidas”. (Entrevistado D)

Ao tratar-se de compartilhamento de informações, considera-se a necessidade da existência de mecanismos, através dos quais possibilitem interação entre as pessoas. Ao buscar-se tais mecanismos, notou-se que estes estão presentes na discussão, no diálogo e na troca de ideias.

Além desta preocupação com o compartilhamento, observou-se grande importância atribuída à preservação dos conhecimentos gerados, para que permaneçam disponíveis para os demais membros, construindo assim mais conhecimento.

"Então, no momento, estamos com uma grande preocupação de preservar, pros novos desenvolvimentos esse conhecimento, mas eu diria para você que em termos de disseminar é uma preocupação que a gente tem, mas que a gente não o faz no momento". (Entrevistado A)

Já sobre a relação da comunicação e conhecimento, foi abordada a questão da produção de conhecimento, e foi constatado na organização em estudo que esta pode surgir de ideias, por meio de pesquisas, estudos, interações com universidades, com o mercado e entre os colaboradores.

"Olha, ele ocorre de várias formas, mas a origem de um novo conhecimento ele se dá por uma ideia". "A gente foi à busca deste conhecimento na universidade, depois capacitamos um pesquisador nesta área e conseguimos lançar o produto. Tudo isto envolveu geração de conhecimento, mas o principio foi a ideia do novo produto e assim que se dá”. (Entrevistado A)

"Você faz uma ponte entre o mercado e a universidade, esta ponte é condição para que você desenvolva novos conhecimentos. (...) A gente precisa de muitos artigos, de muitas revistas que estão na área então isto traz conhecimento técnico, que você precisa junto com ele a interação de mercado, as necessidades de mercado, 
entender as necessidades de seu fornecedor (...) O conhecimento vem da sua interação com o mercado, da sua interação com os seus estudos". (Entrevistado D).

As entrevistas mostram um aspecto não discutido no referencial teórico, que é a extensão da gestão do conhecimento para além da organização, no que se refere à interação com universidades e centros de pesquisa em busca de conhecimentos. Ressalta-se esta relação por envolver questões comunicacionais.

Também foi evidenciado que pode ocorrer produção de conhecimento através da troca de experiências e habilidades dos indivíduos, como segue a opinião do entrevistado:

"Eu vou te falar como P\&D, o conhecimento vem da sua interação com o mercado, da sua interação com os seus estudos, com os seus envolvimentos, se eu não me engano a gente não tem no $\mathrm{P} \& \mathrm{D}$ no mínimo ninguém que não tenha no mínimo mestrado de pesquisador, então já existe uma bagagem, essa bagagem não é o título que importa, mestre doutor, ou o título, mas é o que tem por traz disso que vale". (Entrevistado D)

Considerando a construção de conhecimento na Angelus, notou-se questões teóricas relacionadas à espiral de Nonaka e Takeuchi (1997). Foi identificado nos depoimentos que, de fato, na externalização ocorre a articulação do conhecimento tácito em conhecimentos explícitos normalmente provocada pelo diálogo ou pela reflexão coletiva, na combinação, há conversão de conhecimento explícito para explícito através do registro de conhecimentos, a internalização alcançada por meio do "aprender fazendo" e, por fim, da socialização, na qual ocorre a conversão de conhecimento tácito para tácito, através da troca de experiências.

Assim sendo, a construção de conhecimento na organização por meio da comunicação, ocorre não apenas através da troca de informações e conhecimentos, mas depende essencialmente da situação e das pessoas envolvidas, da aproximação e do relacionamento entre elas (ANGELONI, 2009). A gestão do conhecimento deve estimular a cooperação entre as pessoas que interagem na organização, enfatizando os mecanismos de compartilhamento, circulação e aperfeiçoamento dos conhecimentos produzidos (CANONGIA et al., 2004).

\section{CONSIDERAÇÕES FINAIS}

\begin{tabular}{l|l|l|l|l|l|l|}
\hline (C) Rev. digit. bibliotecon. cienc. inf. & Campinas, SP & v.11 & n.2 & p.98-122 & maio/ago. 2013 & ISSN 1678-765X \\
\hline
\end{tabular}


Observou-se na empresa Angelus Indústria de Produtos Odontológicos S/A, especificamente no setor de Pesquisa e Desenvolvimento, certa preocupação com a gestão do conhecimento, principalmente em relação à contínua produção de novos conhecimentos, bem como um intenso cuidado para que estes não se percam, sendo que são documentados, para que sejam acessados sempre que necessário. Viu-se que o aspecto informacional da comunicação é realmente mais presente do que o aspecto relacional. Contudo, foi possível perceber indícios de valorização do diálogo e da conversação, elementos estes que extrapolam as questões dado, informação e conhecimento.

"Eu acho que muito mais que seminários é o dia a dia de você estar acompanhando de perto e tirando dúvidas". Você precisa interagir com o marketing que ele vai te dizer do que ele precisa e então essa somatória, no ponto que você der a conversa, este "brainstorming" que a gente costuma fazer no começo é a parte mais importante eu acho". (Entrevistado D).

"Então se todos conversarem melhor e se todos estiverem entrosados, fica mais fácil trabalhar”. (Entrevistado F).

Neste processo, emerge a comunicação, que diante da presente perspectiva se destaca como contribuição o fato de a organização ter os relacionamentos interpessoais e intersetoriais. Nota-se que o ambiente organizacional contribui para que a comunicação envolva indivíduos de distintos setores. As interações ocorrem através da combinação entre estrutura, a qual possibilita a comunicação em todas as direções, e o alcance do objetivo de desenvolver projetos continuamente, que demandam a participação de uma equipe interdisciplinar que, entre si, buscam o compartilhamento do conhecimento para sua execução.

Considerando que a Angelus entende que o setor de Pesquisa e Desenvolvimento é estratégico para a sustentabilidade do seu negócio, pode-se afirmar que o setor precisa ser alimentado incessantemente por novos conhecimentos dependentes fundamentalmente da comunicação, tanto a relacional quanto a informacional. Desta forma entende-se que não se constrói conhecimento sem comunicação.

As discussões aqui apresentadas sugerem o desenvolvimento de estudos futuros que observem a comunicação eficaz como aspecto informacional e relacional 
possibilitando acesso aos conhecimentos tácito e explícito que podem vir a constituir o conhecimento organizacional.

\section{REFERÊNCIAS}

ALBAGLI, S.; MACIEL, M. L. Informação e conhecimento na inovação e no desenvolvimento local. Ciência da Informação, v.33, n.3, p.9-16, 2004.

ALCARÁ, A. R. et al. Fatores que influenciam o compartilhamento da informação e do conhecimento. Perspectivas em Ciência da Informação, v.14, n.1, p.170-191, 2009.

ALVARENGA, G. M. O conhecimento organizacional: uma aproximação ao cotidiano. In: MARCHIORI. M. Faces da cultura e da comunicação organizacional. São Caetano do Sul: Difusão, 2008.

ALVARES, L.; BAPTISTA, S. G.; ARAÚJO JR, R. H. Gestão do conhecimento: categorização conceitual. Em Questão, Porto Alegre, v. 16, n. 2, p. 235-252, 2010.

ANGELONI, M. T. Elementos intervenientes na tomada de decisão. Ciência da Informação, Brasília, v. 32, n. 1, p.17-22, 2003.

Comunicação nas organizações da era do conhecimento. São Paulo: Atlas, 2009.

BARRETO, A. A. A questão da informação. São Paulo em Perspectiva, São Paulo, v.8, n.4, p.3-8, 1994.

BERLO, D. K. O Processo da Comunicação: Introdução á Teoria e à Prática. São Paulo: Martins Fontes, 1999.

CAMATTI, T. B.; FACHINELLI, A. C. Comunicação como diferencial estratégico na gestão do conhecimento das organizações. Conexão - Comunicação e Cultura, Caxias do Sul, v.9, n.17, p.161-178, 2010.

CAMPOS, L. F. B. Análise da nova gestão do conhecimento: perspectivas para abordagens críticas. Perspectivas em Ciência da Informação, v.12. n.1, p.104-122, 2007.

CANONGIA, C. et al. Foresight, inteligência competitiva e gestão do conhecimento: instrumentos para a gestão da inovação. Gestão \& Produção, São Carlos, v.11, n.2, p.231238, 2004.

CARDOSO, O. O. Comunicação empresarial versus comunicação organizacional: novos desafios teóricos. Revista de Administração Pública, Rio de Janeiro, v.40, n.6, p.11231144, 2006. 
CHOO, C. W. A organização do conhecimento: como as organizações usam a informação para criar significado, construir conhecimento e tomar decisões. São Paulo: SENAC, 2003. $426 \mathrm{p}$.

DAZZI, M. C. S.; ANGELONI, M. T. Compreendendo o significado de gestão do conhecimento e a importância da comunicação em seu compartilhamento - um estudo de caso. In: ENCONTRO ANUAL DA ASSOCIAÇÃO NACIONAL DOS PROGRAMAS DE PÓS-GRADUAÇÃO EM ADMINISTRAÇÃO, 28., 2004, Curitiba. Anais... Curitiba: ANPAD, 2004.

DRUCKER, P. Desafios gerenciais para o século XXI. São Paulo: Pioneira, 1999.

FERREIRA, A. B. H. Novo Dicionário da Língua Portuguesa. 2. ed. Rio de Janeiro: Nova Fronteira, 1986.

FLEURY, M. T. L.; OLIVEIRA JR, M. M. Aprendizagem e gestão do conhecimento. In: FLEURY, M. T. L. (Org.). As pessoas na organização. São Paulo: Gente, 2002.

(Orgs.). Gestão estratégica do conhecimento: integrando aprendizagem, conhecimento e competências. São Paulo: Atlas, 2001.

GODOI, C.; BALSINI, C. A pesquisa qualitativa nos estudos organizacionais brasileiros: uma análise bibliométrica. In: SILVA, A.; GODOI, C.; BANDEIRA-DE-MELLO, R. Pesquisa qualitativa em estudos organizacionais: paradigmas, estratégias e métodos. São Paulo: Saraiva, 2006. p.89-112.

GODOY, A. Estudo de caso qualitativo. In: SILVA, A.; GODOI, C.; BANDEIRA-DEMELLO, R. Pesquisa qualitativa em estudos organizacionais: paradigmas, estratégias e métodos. São Paulo: Saraiva, 2006. p.115-146.

GOLDHABER, G. M. Comunicación Organizacional. México: Editorial Diana, 1991.

GONÇALVES, M. A. Os papéis do gerente e a qualidade da informação gerencial. In: ENCONTRO ANUAL DA ASSOCIAÇÃO NACIONAL DOS PROGRAMAS DE PÓSGRADUAÇÃO EM ADMINISTRAÇÃ̃O, 19., Rio de Janeiro. Anais... Rio de Janeiro: ANPAD, 1995.

HALL R. H. Organizações: estrutura e processos. 8. ed. São Paulo: Prentice Hall, 2004.

HEARTLEY, J. F. Case studies in organizational research. In: CASSELL, C.; SYMON, G. Qualitative methods in organizational research: a practical guide. London: Sage, 1995.

HENRIQUE, L. C. J.; BARBOSA, R. R. Gestão da informação e do conhecimento organizacionais: em busca de uma heurística adaptada à cultura brasileira. Perspectiva Ciência Informação, v. 10, n.1, p.4-17, 2005.

KLEIN, D. A. A gestão do capital intelectual: uma introdução. In: A gestão estratégica do capital intelectual: recursos para a economia baseada no conhecimento. Rio de Janeiro: Qualitymark, 1998.

KREPS, G. L. Organizational communication: theory and practice. New York: Longman, 1990. 
KUNSCH, M. M. K. Planejamento de relações públicas na comunicação integrada. 4. ed. São Paulo: Summus, 2003.

LEITE, F. C. L. Gestão do conhecimento científico no contexto acadêmico: proposta de um modelo conceitual. 2006. 240 f. Dissertação (Mestrado em Ciência da Informação) Programa de Pós-Graduação em Ciência da Informação, Universidade de Brasília, Brasília, 2006.

LIMA, F.; BASTOS, F. Comunicação no contexto organizacional: afinal, o que é mesmo que estudamos? In: CONGRESSO BRASILEIRO DE CIÊNNCIAS DA COMUNICAÇÃO, 31 ., 2008, Natal. Anais... Natal: Intercom, 2008.

MAIA, R. C. M.; FRANÇA, V. V. A comunidade e a conformação de uma abordagem comunicacional dos fenômenos. In: LOPES, M. I. V. (Org.). Epistemologia da comunicação. São Paulo: Loyola, 2003. p.187-203.

MARCHIORI, M; CONTANI, M. L.; BUZZANELL, P. Dialogue as a possibility for knowledge in organizations. In: DIALOGUE AND REPRESENTATION CONFERENCE, 13., 2011, Amsterdam. Anais... Amsterdam: John Benjamins, 2012. p. 271-288.

MONTEIRO, N. A.; VALENTIM, M. L. P. Necessidades informacionais e aprendizagem no ciclo de vida de um projeto. Revista Digital de Biblioteconomia e Ciência da Informação, Campinas, v.5, n.2, p.53-66, 2008.

MORESI, E. Inteligência organizacional: um referencial integrado. Ciência da Informação, Brasília, v.30, n.2, p.26-35, 2000.

MURPHY, A. G.; EISENBERG, E. M. Coaching to the craft: understanding knowledge in health care organizations. In: CANARAY, H.; MCPHEE, R. D. (Eds). Communication and organizational knowledge: contemporary issues for theory and pratice. New York: Routledge, 2011. p.264-284.

NONAKA, I.; TAKEUCHI, H. Criação e conhecimento na empresa: como as empresas japonesas geram a dinâmica da inovação. Rio de Janeiro: Campus, 1997.

ORSI, A. Gestão do Conhecimento: os modos de conversão do conhecimento nas incorporações de bases externas. In: ENCONTRO ANUAL DA ASSOCIAÇÃO NACIONAL DOS PROGRAMAS DE PÓS-GRADUAÇÃO EM ADMINISTRAÇÃO. 28., 2004, Curitiba. Anais... Curitiba: ANPAD, 2004.

PEREIRA, M. J. L. B.; FONSECA, J. G. M. Faces da decisão: as mudanças de paradigmas e o poder da decisão. São Paulo: Makron Books, 1997.

PROBST, G.; RAUB, S.; ROMHART, K. Gestão do conhecimento: os elementos construtivos do sucesso. Porto Alegre: Bookman, 2002.

PUTNAM, L. L. Paradigms for organizational communication research: an overview and synthesis. The Western Journal of Speech Communication, v.46, n.2, p.192-206, 1982. 
RIBEIRO, R. R.; MARCHIORI, M. R. Comunicação organizacional dialógica: uma perspectiva de interação nas organizações. Comunicação: Veredas. Revista do Programa de Pós-Graduação em Comunicação UNIMAR, v. 7, p. 173-189, 2008.

ROBBINS, S. P. Administração: mudanças e perspectivas. São Paulo: Saraiva, 2002.

SCHULER, M. et al. Comunicação estratégica. São Paulo: Atlas, 2004.

SHANON, C.; WEAVER, W. The mathematical theory of communication. Urbana: University of Illinois Press, 1949.

SILVA, S. L. Gestão do conhecimento: uma revisão crítica orientada pela abordagem da criação do conhecimento. Ciência da Informação, Brasília, v.33, n.2, p.143-151, 2004.

TAYLOR, J. R. Rethinking the theory of organizational communication: how to read an organization. Norwood: Ablex, 1993.

TEIXEIRA FILHO, J. Gerenciando o conhecimento: como a empresa pode usar a memória organizacional e a inteligência competitiva no desenvolvimento dos negócios. Rios de Janeiro: SENAC, 2000.

TSOUKAS, H; VLADIMIROU, F. What is organizational knowledge? Journal of Management Studies, v.38, n.7, p.973-993, 2001.

TUCKER, M. L.; MEYER, G. D.; WESTERMAN, J. W. Organizational communication: development of internal strategic competitive advantage. The Journal of Business Communication, v.33, n.1, p.51-69, 1996.

VALENTIM, M. L. P. Inteligência competitiva em organizações: dado, informação e conhecimento. DataGramaZero, Rio de Janeiro, v.3, n.4, 2002. Disponível em: <http://www.dgz.org.br/ago02/F_I_art.htm>. Acesso em: 20 abr. 2012.

VASCONCELLOS, C. F; BASTOS, K. H. As dimensões humana, instrumental e estratégica da comunicação organizacional: um estudo teórico e aplicado. In: CONGRESSO BRASILEIRO CIENTÍFICO DE COMUNICAÇÃO ORGANIZACIONAL E RELAÇÕES PÚBLICAS, 3., 2009, São Paulo. Anais... São Paulo: ABRAPCORP, 2009.

VIZER, E. La trama (in) visible de la vida social: comunicación, sentido y realidad. Buenos Aires: La Crujía. 2003.

\section{Como citar este artigo:}

MACIEL, Ana Maria Teixeira; PIMENTEL, Rosana Cristina Vilaça; MARCHORI, Marlene. Comunicação e conhecimento: inter-relações que permeiam o ambiente organizacional. Rev. digit. bibliotecon. cienc. inf., Campinas, SP, v. 11, n. 2, p.98-122, maio/ago. 2013. ISSN 1678-765X. Disponível em: <http://www.sbu.unicamp.br/seer/ojs/index.php/rbci> 